\title{
Invisibilidades da guerra e da paz: Violências contra as mulheres na Guiné-Bissau, em Moçambique e em Angola
}

Invisibilities in War and Peace: Violence against women in Guinea-Bissau, Mozambique and Angola

Invisibilité de la guerre et de la paix : violences contre les femmes en GuinéeBissau, au Mozambique e en Angola

Tatiana Moura, Sílvia Roque, Sara Araújo, Mónica Rafael e Rita Santos

\section{OpenEdition}

\section{Journals}

Edição electrónica

URL: http://journals.openedition.org/rccs/240

DOI: $10.4000 /$ rccs. 240

ISSN: 2182-7435

\section{Editora}

Centro de Estudos Sociais da Universidade de Coimbra

Edição impressa

Data de publição: 1 Setembro 2009

Paginação: 95-122

ISSN: 0254-1106

Refêrencia eletrónica

Tatiana Moura, Sílvia Roque, Sara Araújo, Mónica Rafael e Rita Santos, «Invisibilidades da guerra e da paz: Violências contra as mulheres na Guiné-Bissau, em Moçambique e em Angola », Revista Crítica de Ciências Sociais [Online], 86 | 2009, colocado online no dia 01 dezembro 2012, criado a 30 abril 2019. URL : http://journals.openedition.org/rccs/240 ; DOI : 10.4000/rccs.240 


\section{TATIANA MOURA, SÍLVIA ROQUE, SARA ARAÚJO, MÓNICA RAFAEL, RITA SANTOS}

\section{Invisibilidades da guerra e da paz: Violências contra as mulheres na Guiné-Bissau, em Moçambique e em Angola}

O facto de serem homens os que mais matam e morrem em tempo de guerra declarada tem determinado a invisibilidade e negligência de outros actores envolvidos nestes contextos. As mulheres, em concreto, têm sido o ausente social por excelência nas análises sobre conflitos armados e nas políticas de reconstrução pós-conflito Através de uma abordagem que privilegia a análise de continuuns de violência(s) para além de cenários considerados como guerra oficial, e tendo por base os contextos angolano, guineense e moçambicano, pretende-se demonstrar a proximidade entre zonas de guerra e zonas de paz, nomeadamente no que diz respeito à existência de inseguranças que não são consideradas relevantes no desenho e implementação de políticas levadas a cabo no pós-guerra. Pretende-se, em particular, analisar as formas de violência exercidas contra mulheres nestes contextos.

Palavras-chave: violência contra mulheres, insegurança em tempo de paz, estratégias de resposta à violência

\section{Introdução: pós-violências?}

As últimas décadas do século xx testemunharam uma acumulação de guerras: a Guerra-Fria e o seu final, guerras civis prolongadas, conflitos sem nome que viriam a ser chamados de "novas guerras" (Kaldor, 2001). Mas ficaram também marcadas pela criação de políticas e programas de resposta a conflitos armados. Apesar de multidimensionais e multifuncionais, as várias estratégias de resolução de conflitos e de reconstrução das sociedades afectadas foram implementadas de forma padronizada em diferentes contextos. A viragem para o século xxi tem revelado a desadequação de conceitos e políticas. Como refere Ramsbotham,

[O] termo consolidação da paz pós-conflito, apesar da nomenclatura das Nações Unidas, é erróneo [...]. 'Pós-conflito’ é precisamente o que não é. Pelo contrário, o acordo de paz não representa o final do conflito, e sim o meio através do qual as partes esperam resolver as questões não resolvidas da guerra (2000: 173). 
As guerras do final do século xx corresponderam a uma intensificação de violências que se foram acumulando, ao serem marginalizadas e invisibilizadas, por não serem consideradas relevantes. E o fim dessas guerras, com assinaturas formais de acordos de paz, não significou necessariamente a resolução dos interesses antagónicos que lhes estiveram subjacentes. Ou seja, podemos afirmar que os actuais contextos de pós-conflitos não correspondem, necessariamente, a um período de pós-violências. Pelo contrário, correspondem frequentemente a uma etapa de acumulações de velhas e novas violências, de velhas e novas inseguranças, que ao não serem tidas em consideração constituem formas embrionárias de um novo pré-guerra.

A (re)conceptualização das guerras tem suscitado o questionamento da separação entre guerra e "formas menores" de violência, mostrando precisamente a importância da noção de continuuns de violências como expressão de uma realidade em que a guerra não é um facto social isolado, mas antes algo que impregna, como sistema cultural, o quotidiano. A guerra deixou de ser, portanto, uma excepção - um momento de intensa irracionalidade e violência, mas com um começo e um fim claros - para se transmutar em expressão "instalada" de uma cultura de violência, com uma intensidade e uma radicalidade inconstantes (Moura, 2007).

As novas guerras diferiram da paz violenta em escala ou grau, mais do que em condições absolutas ou opostas (Duffield, 2001). Mesmo em contextos de paz institucionalizada - seja em sociedades que atravessam um período de reconstrução pós-bélica, seja em sociedades saídas de regimes autoritários que vivem um período de transição democrática - identificam-se condições que permitem a perpetuação das novas guerras, e que, acima de tudo, contribuem para a reconfiguração e perpetuação de novos e velhos tipos de violência.

Em sociedades que vivem processos de reconstrução pós-guerra dominados por preocupações de curto prazo e por um quadro de referências políticas, económicas e sociais de recorte neo-liberal, facilmente se opera uma transferência da violência armada anterior para uma violência social disseminada. Como salienta Kaldor (2000), na medida em que os vários actores das novas guerras dependem da violência continuada, os cessar-fogos e os acordos de paz correspondem frequentemente a tréguas ou a pausas que não lidam com as relações sociais de poder subjacentes. Não lidam, sobretudo, com velhas violências que existiam já no período anterior ao conflito, como as várias violências contra mulheres, que, no período pós-guerra, se tornam potencialmente mais letais em virtude da disponibilidade de armas de fogo. 
Os olhares estereotipados sobre as realidades têm sempre resultados perversos. $\mathrm{O}$ facto de serem homens os que mais matam e morrem em tempo de guerra declarada fez com que se fechassem os olhos e se negligenciassem outros actores envolvidos nestes contextos. As mulheres, em concreto, têm sido o ausente social por excelência nas análises sobre conflitos armados e nas políticas de reconstrução pós-conflito.

Esta invisibilidade das guerras prolonga-se para o período pós-bélico. Se durante o conflito armado determinados grupos não são considerados como intervenientes relevantes, que participaram e sofreram os impactos das guerras de forma diferenciada - como é o caso de mulheres e crianças -, no período de reconstrução pós-guerra as suas necessidades permanecem invisibilizadas. Por outro lado, fazer equivaler o período de pós-guerra a um período de paz tem exigido o silenciamento de práticas violentas, que assumem novas características.

No entanto, as manifestações dos vários tipos de violências, que constituem fontes de insegurança, apresentam-se em várias escalas, desde a intersubjectiva (interpessoal) à internacional. Através de uma abordagem que privilegia a análise de continuuns de violência(s) para além de cenários considerados como guerra oficial, procuramos neste artigo demonstrar a proximidade entre zonas de guerra e zonas de paz, nomeadamente no que diz respeito à existência de inseguranças que não são consideradas relevantes no desenho e implementação de políticas levadas a cabo no pós-guerra. Pretendemos, em particular, analisar as formas de violência exercidas contra mulheres nestes contextos. Para isso, reportamo-nos privilegiadamente aos contextos de três países onde as manifestações dessas formas de violência adquirem uma expressão preocupante, que importa portanto analisar: Guiné-Bissau, Angola e Moçambique. ${ }^{1}$

\section{Violências contra mulheres: permanências da guerra e da paz}

Apesar de, em alguns casos, a vasta participação das mulheres nas guerras de libertação e civis ter levado a repensar as relações sociais com os homens e o tipo de sociedade a edificar (Casimiro, 2004: 141), em geral não se alterou

\footnotetext{
${ }^{1} \mathrm{O}$ artigo sintetiza os principais resultados de um estudo realizado sobre violências contras as mulheres, no âmbito do projecto de investigação "Peacebuilding processes and state failure strategies: lessons learned from three former Portuguese colonies" (2006-2008), financiado pela Fundação Ford, que envolveu trabalho de campo em três países: Guiné-Bissau, Angola e Moçambique. Além da análise bibliográfica e documental, foram realizadas entrevistas individuais com: académicos e advogados especializados no domínio da violência contra as mulheres; líderes e técnicos de organizações que trabalham com mulheres, jovens e questões relacionadas com violência; mulheres vítimas de violência. Foram ainda realizados focus groups (jovens, mulheres e homens) sobre violência contra as mulheres.
} 
significativamente o seu estatuto em períodos de pós-guerra. De facto, as relações reais de poder continuam muitas vezes a determinar a submissão das mulheres e a dificultar a denúncia de actos de violência baseados no sexo das vítimas.

A inexistência de dados, estudos e análises sobre violências (directas) contra mulheres e jovens do sexo feminino na Guiné-Bissau, em Angola e em Moçambique (ainda que neste último caso esse défice seja menor), torna difícil a tarefa de traçar com precisão uma tipologia das violências cometidas contra estes grupos, ou aferir a sua evolução no pós-conflito armado. No que diz respeito às violências contra mulheres, os silêncios são muito mais reveladores do que o ostensivamente demonstrado. Ou seja, a visibilidade que têm assumido recentemente algumas formas de violência, nomeadamente a Mutilação Genital Feminina (MGF), coexiste com a invisibilidade de outras práticas violentas normalizadas que têm como vítimas, sobretudo, mulheres e jovens do sexo feminino.

Ao questionar a existência de formas de violência contra mulheres nestes contextos identificam-se sobretudo práticas ditas tradicionais, ${ }^{2}$ como se nada mais existisse. Quando se fala em violência sexual, parece que esta só afecta jovens de ambos os sexos, sendo frequentemente algo normalizado para as mulheres adultas.

Certo é que diferentes violências contra o sexo feminino, que ocorrem sobretudo no âmbito privado (familiar, comunitário) ou informal (trabalho informal, trabalho de rua, trabalho infantil), surgem, por um lado, da desigualdade de poder entre homens e mulheres; surgem ainda, por outro lado, da ausência de controlo social e político face às violências, controlo esse remetido para o âmbito do "tradicional", do "informal", do "não estatal" e para formas de compensação e justiça indiferentes à necessidade de transformação da realidade social. Finalmente, essas violências decorrem também da quase ausência de políticas de protecção e resposta.

As violências contra mulheres são permanências. Embora vão adquirindo formas distintas, são um dos elementos de ligação entre a paz e a guerra. As formas de violência estrutural que têm como um dos efeitos a guerra (violência directa colectiva e organizada) mantêm-se em tempo de paz, provocando outras formas de violência directa. O que um período de paz formal tem de diferente do conflito armado é a ilusão de maior igualdade ou de melhoria. A paz dá um pouco mais de conforto e esperança.

$\overline{2}$ Como o casamento forçado ou a MGF. 


\section{Guiné-Bissau}

Os resultados positivos da ausência de guerra são, por vezes, ultrapassados pela expectativa permanente de guerra e a manutenção da instabilidade política e militar, dirigida para outros meios não tão letais (golpes de Estado, assassinatos políticos, violações de direitos humanos, etc.). $\mathrm{Na}$ Guiné-Bissau esta expectativa mantém-se, quotidianamente, mais de dez anos depois do conflito. Nos meios rurais, o conflito armado aumentou a pressão sobre os recursos com que as mulheres trabalham. Nos meios urbanos, assiste-se a um aumento da violência institucional, económica e social, visível na deterioração das condições de vida e na primazia da lógica de sobrevivência do dia-a-dia.

Os impactos económicos do conflito na Guiné-Bissau são anormalmente graves, tendo em conta a duração e o tipo de conflito. ${ }^{3}$ Segundo um relatório do Banco Mundial, a situação económica da Guiné-Bissau no pós-guerra supera, para pior, a do Ruanda pós-genocídio (World Bank, 2005). De acordo com o PNUD, as mulheres guineenses são as antepenúltimas, a nível mundial, em termos de rendimentos (estimated earned income) - 487 PPP US\$, sendo esse valor para os homens de 963 PPP US\$. Esta situação pode explicar-se, por um lado, pela situação económica e social antecedente à guerra e, por outro, pela incapacidade e/ou ausência de respostas adequadas no que diz respeito às políticas pós-conflito armado. Parece, assim, existir uma pauperização acentuada da população em geral, o que corresponde a uma percepção de degradação das condições de vida em relação ao período antes da guerra para 76,6\% dos guineenses (World Bank, 2005: 27).

As mulheres dos 31 aos 45 anos são menos atingidas pela pobreza monetária do que os homens, contrariamente às outras faixas etárias. No entanto, a "pobreza humana" é mais acentuada nas mulheres em todas as faixas etárias e todas as regiões (ESNU, 2006). Significa isto que, na Guiné-Bissau, a situação económica das mulheres após a guerra piorou, tendo todavia aumentado o seu peso económico através da sua forte implicação na economia informal. Sendo as mulheres predominantes neste sector, tiveram que refazer as redes de sobrevivência normais (para além da crise); algumas perderam marido, outras emigraram. No entanto, apesar de muito visíveis nas ruas e mercados, noutras dimensões essenciais permanecem invisíveis. No contexto da economia formal, as mulheres, em tempos de crise, são as primeiras a ficar sem emprego. As novas oportunidades de sobrevivência

\footnotetext{
${ }^{3} \mathrm{O}$ conflito político-militar durou 11 meses, circunscreveu-se à cidade de Bissau e, tendo grande parte da população fugido para o interior, não se pautou por um grande número de baixas civis ou pela sua utilização como alvos.
} 
passam também, muitas vezes, pelo recurso à prostituição e o retorno a velhas obrigações, recuperando práticas como o casamento precoce.

Outro tipo de violência estrutural com impactos graves em termos de sobrevivência diz respeito à própria capacidade de manutenção da vida, dificultada por um sistema de saúde em falência, não funcional e inacessível em termos económicos. Na realidade, permitir a morte de pessoas porque não existe prática de cuidados de saúde ou porque estas não os podem pagar é uma forma de violência que aproxima a guerra da paz.

Esta tendência agravou-se especialmente com o conflito de 1998-99. A esperança de vida tendeu a diminuir: em 1992 era de 47 anos e em 2002 era já só de 45 anos. Desde 1975, a esperança média de vida das mulheres regista um aumento de 7,9 anos, enquanto a dos homens regista um aumento ligeiramente superior, de 8,2 anos (mantendo-se, no entanto, inferior).

$\mathrm{Na}$ realidade, apesar do panorama geral de condições de acesso à saúde na Guiné-Bissau ser desolador, existem problemas que afectam especificamente as mulheres. Por exemplo, em $32 \%$ dos casos, as mortes de mulheres em idade fértil estão ligadas à maternidade. A Guiné-Bissau é, segundo a Save the Children, um dos piores países para ser mãe. ${ }^{4}$ Com a fraca cobertura de equipamentos e pessoal de saúde, a falta de informação e a não gratuitidade real dos cuidados, a situação das mulheres, sobretudo das mães, tem vindo a deteriorar-se. A taxa de mortalidade materna, que aumentou drasticamente no período da guerra, mantém-se extremamente elevada (ver tabela).

\begin{tabular}{|c|c|c|c|}
\hline Anos & $1990-1996$ & $1997-2000$ & $2000-2004$ \\
\hline $\begin{array}{c}\text { Taxa de mortalidade materna por } \\
100000\end{array}$ & 822 & 1100 & 822 \\
\hline
\end{tabular}

Fonte: Banco Africano de Desenvolvimento (2006: 24)

Isto acontece quando a tendência geral na África Ocidental é para uma diminuição progressiva global das mesmas taxas (segundo o Banco Africano de Desenvolvimento, a média geral na África Ocidental é de 660 mortes por 100 mil). Os avanços tecnológicos e de cobertura sanitária parecem não se revelar ao mesmo nível que se revelam, por exemplo, na diminuição da mortalidade infantil (redução de 20,8\% entre 1990 e 2005: de 145 para 114 por mil; cf. Banco Africano de Desenvolvimento, 2006).

Apesar das melhorias na escolarização das raparigas nos países africanos, sobretudo devido à urbanização, estas continuam preteridas, face aos

\footnotetext{
${ }^{4}$ Cf.: http://www.savethechildren.org/newsroom/2006/a-mothers-day-report-card.html
} 
rapazes, no acesso à escola, o que lhes dificulta ainda o acesso a determinadas funções e a melhoria das suas actividades. Neste aspecto, a Guiné-Bissau não foge à regra. No ensino primário, o rácio é de 83 raparigas para 100 rapazes; no secundário a distância é ainda maior, com um rácio de 44 para 100 (ESNU, 2006). A taxa de analfabetismo é de $76,2 \%$ para as mulheres e 47,7\% para os homens (ibid.). Verificando-se a redução da já quase nula presença educativa do Estado fora das cidades e uma pressão discriminatória inevitável, promovida nos anos oitenta pelas instituições financeiras internacionais e por medidas que dificultaram o acesso à educação nos meios rurais e nas idades mais avançadas (Lepri, 1993), registou-se nesta matéria um avanço demasiado parco para as expectativas criadas com a independência.

\section{Moçambique}

Os impactos imediatos do conflito armado em Moçambique sobre as mulheres revelaram-se, no pós-conflito, através da sua marginalização pelos programas de desmobilização, desarmamento e reintegração. Jacobson (2006) critica o programa implementado pela ONUMOZ, que excluiu e marginalizou as mulheres combatentes, bem como as mulheres dependentes. Por exemplo, os pacotes de desmobilização a que as primeiras tinham direito incluíam apenas roupa interior masculina. Relativamente às mulheres dependentes, o programa partiu do pressuposto que cada soldado teria apenas uma mulher, o que não era necessariamente verdade. Existem relatos, principalmente de 1993 e 1994, de homens forçados a "escolher" qual das esposas era a oficial, deixando à sua sorte as mulheres que, juntamente com os seus filhos, não eram escolhidas. Esta situação conduziu a um aumento considerável de indigência e prostituição nas zonas militares, agravada, entre 1992 e 1994, pela presença de tropas internacionais enviadas para proteger a população.

$\mathrm{Na}$ década e meia que sucedeu ao fim do conflito armado, a situação das mulheres permanece estruturalmente desvantajosa, apesar das claras melhorias em áreas como a educação ou a saúde. De acordo com os censos de 2007, em Moçambique as mulheres compõem 52\% da população. Segundo projecções do Instituto Nacional de Estatística Moçambicano (INEM), realizadas a partir dos censos de 1997,, 5 em 2006 a esperança de vida das mulheres seria de 49,3 anos e a dos homens de 45,5, valores que tendem a ser instáveis, pois dependem em larga medida da evolução da epidemia do HIV/SIDA.

5 Os dados relativos ao Censo de 2007 ainda não estão disponíveis na sua totalidade. 
Ainda que, nos últimos anos, se verifiquem progressos na educação, as raparigas têm menor probabilidade de obter educação escolar em todos os níveis do sistema. Se a taxa de analfabetismo masculino desceu de 40,2\% em 2000 para $34,4 \%$ em 2004, o analfabetismo feminino desceu no mesmo período de $71,2 \%$ para $66,2 \%$. As desvantagens das mulheres começam muito cedo. Em 2004, as mulheres constituíam 45\% dos inscritos na EP1 (Escola Primária, nível 1), 40\% na EP2 (Escola Primária, nível 2) e 37\% no primeiro grau da educação secundária (PNUD, 2006b). No ano de $2002 / 2003$, apenas $32,2 \%$ dos alunos inscritos nas universidades eram mulheres. Nas zonas rurais, o problema aumenta substancialmente. De acordo com o Questionário de indicadores básicos de bem-estar (INE, 2001), a taxa de analfabetismo das mulheres sobe de $44,9 \%$ nas zonas urbanas (17,4\% para os homens) para $83,1 \%$ nas zonas rurais ( $52,1 \%$ nos homens). Os resultados do mesmo questionário apontavam quatro causas para o abandono escolar das mulheres entre os seis e os dezassete anos. Em primeiro lugar, a ideia de que o ensino não serve; em segundo lugar, os custos; em terceiro lugar, a distância do estabelecimento de ensino; e, por fim, a gravidez indesejada. O estudo Para além das desigualdades 2005 (PAD, 2005) e o Relatório nacional do desenvolvimento bumano 2005 (RNDH, 2005) acrescentam outras razões, como o casamento precoce, as percepções negativas sobre o sucesso das raparigas na escola e o assédio e abuso sexual das raparigas protagonizados por professores e alunos (Fórum Mulher e SARDC WIDSAA, 2006; PNUD, 2006b).

A possibilidade de acesso das mulheres ao emprego formal é inferior à dos homens, em particular devido às suas menores qualificações. As horas de trabalho, a distância a percorrer até ao local de trabalho, a natureza do emprego, bem como outros factores culturais e sociais contribuem também para essa realidade (Fórum Mulher e SARDC WIDSAA, 2006). Segundo o RNDH 2005, menos de $10 \%$ da população activa tem um emprego formal (PNUD, 2006b). De acordo com o PAD, num inquérito realizado pelo Instituto Nacional de Estatística Moçambicano em 2000/2001, as mulheres constituíam apenas 16\% da população empregada da amostra (Fórum Mulher e SARDC WIDSAA, 2006).

Isto não significa que a taxa de ocupação das mulheres seja inferior à dos homens. Os resultados do Inquérito integrado à força de trabalho, desenvolvido entre 2004 e 2005, revelam uma taxa de ocupação feminina de $77,6 \%$ e masculina de 72,3\%. Estas percentagens descem nas zonas urbanas, ainda que não se invertam, passando para $62,8 \%$ para as mulheres e $54,1 \%$ para os homens (INE, 2006a). É no sector informal da economia que grande parte das mulheres encontra uma das principais fontes de 
rendimento (Fórum Mulher e SARDC WIDSAA, 2006). De acordo com os resultados do inquérito ao sector informal realizado em 2004, as mulheres constituem $58,5 \%$ dos trabalhadores informais com mais de 7 anos, valor que aumenta no sul do país $(65,8 \%)$ e nas zonas urbanas $(60,1 \%)$. A grande maioria das actividades do sector informal está ligada à agricultura (91\% do trabalho informal), mas também na indústria, construção, comércio, turismo e em outros serviços existe emprego informal (INE, 2006b).

De acordo com o relatório PAD 2005, grande parte das mulheres moçambicanas tem dificuldade de acesso a serviços apropriados de saúde reprodutiva. Apesar de existir um programa nacional de saúde reprodutiva, nem todas as mulheres, especialmente nas zonas rurais, beneficiam dele. A epidemia do HIV/SIDA contribui para a degradação da situação da mulher e o défice de recursos por parte do Estado para apoiar este sector.

De acordo com os Resultados do Inquérito Demográfico e de Saúde (INE, 2003), a taxa de mortalidade materna era, à data de realização do inquérito, 408/100.000. O mesmo inquérito revela que, em 2003, 80,7\% dos partos nas zonas urbanas eram acompanhados por um profissional de saúde, valor que descia para $34,2 \%$ nas zonas rurais. Estas taxas variam substancialmente no país. Se na cidade de Maputo a percentagem de partos acompanhados por profissional era de $89 \%$, na província de Cabo Delgado era de $31 \%$.

No que diz respeito à percentagem de mães que receberam cuidado pré-natal (por um médico ou enfermeira-obstetra), os valores são mais elevados e mais aproximados, sendo $97,1 \%$ nas zonas urbanas $(99,5 \%$ na cidade de Maputo) e 78,9\% nas zonas rurais (a província da Zambézia apresenta uma percentagem substancialmente mais baixa que as outras $-57,9 \%-$, sendo a única com uma taxa inferior a $80 \%$ ).

Em 2005, sete dos 27 ministros e quatro dos 13 vice-ministros eram mulheres. O governo era composto por mais seis mulheres do que o anterior, tendo-se passado de uma representação de 12,5\% para 24,4\%. Em 2003 foi nomeada uma mulher primeira-ministra e têm sido nomeadas mulheres para pastas tradicionalmente associadas a homens, como a dos negócios estrangeiros e cooperação, justiça e recursos minerais. Na legislatura actual (2004-2009), 35,6\% dos membros do parlamento são mulheres, tendo-se registado um aumento de 4,4\% em relação à legislatura anterior (Fórum Mulher e SARDC WIDSAA, 2006).

\section{Angola}

À semelhança da maior parte das situações de conflito armado, um dos resultados da desestruturação e desintegração familiar e do deslocamento forçado de famílias durante o conflito angolano foi a adopção, por parte 
das mulheres, de um papel mais preponderante tanto dentro da unidade familiar como nas suas comunidades. De facto, o desenrolar do conflito exigiu que muitas mulheres assumissem a liderança de famílias monoparentais (Ducados, 2000), ${ }^{6}$ levando à transformação dos papéis sociais, com a acumulação de mais responsabilidades no sustento e garantia de segurança e sobrevivência da família. O acentuar das práticas da poligamia e o crescente número de separações, divórcios e desintegração de unidades familiares alargadas dificultaram a conciliação do trabalho fora de casa com a educação e acompanhamento das crianças.

O enorme fluxo de deslocados internos para Luanda durante o conflito levou a um crescimento descontrolado e desorganizado da cidade, com grande parte da população deslocada a instalar-se em bairros periféricos e semi-periféricos da capital, os musseques, caracterizados pela pobreza extrema e falta de infraestruturas básicas. Este contexto exigiu que as mulheres ficassem responsáveis pela sobrevivência económica da unidade familiar, com a maior parte das famílias dos musseques a serem chefiadas por mulheres (viúvas ou mulheres que sustentam maridos desempregados), com um conhecimento reduzido da língua portuguesa, pouco ou nada alfabetizadas e sem experiência e educação formal para competir no mercado de trabalho luandense, com pouca oferta no mercado formal. Esta realidade traduz-se no envolvimento da grande maioria destas mulheres no cultivo de pequenas parcelas de agricultura peri-urbana e principalmente em pequenos negócios dentro do mercado informal - sobretudo como vendedoras ambulantes. Muitas destas mulheres arriscam a sua integridade física quando atravessam fronteiras internacionais para comprar mercadorias, ${ }^{7}$ quando perdem tudo o que compraram para pagar subornos às autoridades policiais, quando viajam longas distâncias para os vários mercados dentro e fora das cidades, tanto em Luanda como em outros centros urbanos do país. Embora não existam estatísticas oficiais relativamente ao número de mulheres que se dedicam a este tipo de actividade, começam a surgir movimentos organizados para a defesa dos seus interesses.

Para além disso, o maior controlo e fiscalização efectuado pelos fiscais do Estado parece reflectir o volume considerável de transacções comerciais por elas efectuadas. Uma consequência adicional da precariedade associada

\footnotetext{
${ }^{6}$ Algumas estimativas (WIDTECH, 1997) referem que cerca de um terço das famílias angolanas são chefiadas por mulheres, mas a percepção dos entrevistados no âmbito da pesquisa que serve de base a este texto é de que este número será significativamente maior.

${ }^{7}$ Actividade mais comum no sul do país, com viagens à Namíbia para comprar mercadorias para revenda.
} 
à actividade das zungueiras ${ }^{8}$ é o facto de, na maior parte dos casos, nas grandes zonas urbanas e suas periferias estas mulheres terem que deixar os filhos sozinhos em casa, sem supervisão ou a cargo dos seus irmãos mais velhos, sendo as raparigas frequentemente as mais afectadas, uma vez que esta realidade as impede muitas vezes de frequentar a escola.

As mulheres de áreas rurais foram as principais vítimas de actos de violência e abuso sexual por parte dos soldados durante a guerra e continuam a ser afectadas no período pós-conflito, nomeadamente por minas anti-pessoais, durante a realização de tarefas como a recolha diária de água e madeira e trabalho agrícola. A sobrevivência da agricultura familiar é ainda afectada pela elevada concentração de terras nas mãos de elites, nomeadamente em áreas de maior densidade populacional, e pela ambiguidade e deficiências da Lei da Terra (Lei ${ }^{\circ}$ 9/2004), que agrava o acesso das comunidades a terras de exploração agrícola. O declínio da actividade agrícola e a consequente diminuição da diversidade alimentar contribuem ainda para a manutenção da taxa de subnutrição. Embora algumas organizações não governamentais tenham implementado projectos de micro-crédito e de apoio ao acesso à terra, a realidade geral de grande parte das mulheres no espaço rural é ainda de grande precariedade e vulnerabilidade.

A esta dimensão acrescem a crescente desigualdade social, o desemprego, a privatização de serviços de saúde e de educação e o facto de mais de dois terços da população angolana viver abaixo do limiar da pobreza, realidade em que as mulheres são indubitavelmente o grupo mais afectado pela situação de extrema violência económica que se vive no país (PNUD, 2006a).

\section{Violências da paz}

\section{Guiné-Bissau}

As expressões mais frequentes das violências directas em relação às mulheres têm assumido um carácter de permanência, invariável, no que diz respeito à divisão entre pré e pós-guerra. Na realidade, a guerra pode até ser vista como período em que algumas destas violências diminuem de intensidade ou se suspendem e em que outras aumentam de intensidade. No entanto, existem duas grandes características das violências comuns contra as mulheres: primeiro, estão associadas a práticas na comunidade e na família, bem como aos agentes de autoridade ou serviços do Estado; em segundo lugar, são legitimadas e perpetuadas por justificações "culturais", que servem propósitos institucionais, políticos e económicos alargados

\footnotetext{
${ }^{8}$ Mulheres dedicadas ao comércio informal.
} 
ou de determinados grupos. De facto, a paz pode ser, para as mulheres, mais violenta do que a guerra, sobretudo num contexto de normalização crescente da violência.

\section{Violência doméstica}

A amplitude da violência doméstica (dirigida maioritariamente a mulheres) é impossível de determinar neste contexto. A ausência de dados e a escassez das denúncias não nos impede, porém, de lançar pistas de análise sobre a extensão da violência doméstica na sociedade guineense. Sabemos que $51,5 \%$ das mulheres consideram aceitável que o marido lhes bata por diferentes motivos (UNICEF, 2007). A violência física e psicológica é extremamente comum e pode assumir várias formas de relação; mas se nos centrarmos apenas na relação homem-mulher ou pais-filha, estamos a falar de algo extremamente desvalorizado e não necessariamente encarado como violência, mas por exemplo como medidas educativas dos homens.

As práticas de violência doméstica devem ser analisadas tendo em conta os impactos nos sistemas organizativos, nas relações de poder e nas transformações sociais e económicas (urbanização, desemprego, aumento da economia informal). A perda de algumas prerrogativas pelos homens (acesso directo a recursos, perda de autoridade, incremento dos rendimentos das mulheres) parece aumentar os riscos de violência doméstica.

\section{Heranças}

O facto de as mulheres terem uma esperança de vida superior à dos homens, aliado ao facto de grande parte dos casamentos se fazerem entre homens mais velhos e mulheres mais jovens, leva a que a questão das heranças deixadas por cônjuges seja praticamente um assunto de mulheres. O problema radica, por um lado, na discriminação das mulheres no que diz respeito às regras de costume sucessório (em diferentes etnias as mulheres estão afastadas da propriedade, quer enquanto cônjuges, quer enquanto filhas); e, por outro, no facto de no próprio Código Civil guineense a posição sucessória dos cônjuges não assumir o mesmo carácter privilegiado, como acontece, por exemplo, no direito português (Mané, 2004: 40). Não só as mulheres correm o risco de ser despojadas de todos os seus bens (do marido), como os próprios filhos - assumindo a família do marido (irmãos e sobrinhos, muitas vezes) a prioridade na sucessão, ao nível dos costumes. Em alguns casos, embora isso tenda aparentemente a cair em desuso, as próprias mulheres constituem parte dos bens herdados pelos irmãos ou sobrinhos do falecido, obrigados a "tomar conta" da família do familiar, acontecendo, muitas vezes, que a mulher se torna uma empregada da família do marido falecido. 
Outro problema de acesso a heranças diz respeito à discriminação entre as várias esposas, devido aos sistemas de casamento poligâmico. Há quem defenda que, neste aspecto, o problema da herança se resolve quando se institucionalizar e legalizar a poligamia, já que, embora se reconheçam como uniões de facto os casamentos costumeiros ou de outras pertenças religiosas, apenas se consideram a partir da sua singularidade (ou seja, natureza não poligâmica). Há, no entanto, quem encare esta situação como um retrocesso no estatuto legal das mulheres. Actualmente parece aumentar o número de mulheres que se insurgem contra estas práticas e costumes; todavia, não está garantido o devido apoio jurídico e económico para que estas reivindicações possam ser levadas a cabo com sucesso.

\section{Violência sexual: violações e exploração}

Segundo a Equipa das Nações Unidas na Guiné-Bissau, em 2004 e 2005 a polícia e as ONG registaram cem casos de violência contra crianças, $70 \%$ ligados a abuso sexual, na maioria dizendo respeito a meninas entre os 12 e os 16 anos (ESNU, 2006). Tendo em conta que grande parte dos casos não chega ao conhecimento das autoridades nem das ONG, por se resolverem informalmente dentro ou entre famílias ou porque as meninas não falam ou não têm família, e que não existe qualquer estudo para identificar a amplitude do problema da prostituição e exploração sexual infantil, parece-nos que a violação sexual de meninas é um dos fenómenos mais alarmantes e para o qual é urgente encontrar respostas. Segundo Elsa Santiago (2007), os agressores são normalmente um familiar, alguém próximo da família ou um vizinho. A resolução destes casos resulta muitas vezes numa compensação pecuniária ou em géneros à família da vítima, não existindo qualquer tipo de punição para o agressor ou ajuda psicológica e material à própria vítima.

Como salientam os técnicos das poucas organizações que se dedicam a ajudar crianças vítimas de vários abusos, nomeadamente violência sexual, a maior parte dos casos nem sequer chega a discussão informal ou judicial e, quando chega a vias judiciais, é frequente que pessoal médico e actores judiciais dificultem o andamento dos processos, provavelmente mediante compensações por parte das famílias dos agressores, chegando mesmo à humilhação e desconsideração dos depoimentos das meninas em tribunal. ${ }^{9}$

\footnotetext{
9 Baseamo-nos aqui no depoimento fornecido por uma técnica da ONG INDE relativo ao caso de violação de duas meninas por um vizinho e que, com a ajuda da ONG, chegou a tribunal, tendo depois os juízes ridicularizado as meninas em causa.
} 
Foram também referidos por parte de militares em algumas entrevistas casos de abuso sexual de meninas que trabalham na rua, bem como de civis, alguns deles de cargos influentes, resultando até na morte das vítimas, e contra os quais nenhuma providência foi tomada devido à sua influência política, económica ou social.

\section{Meninas de criação}

O fenómeno dos/as meninos/as de criação surge como método de distribuição dos encargos das famílias, enviando os seus filhos para criação num outro agregado, muitas vezes parte da própria família (como tias e sobrinhas). Não sendo um fenómeno necessariamente negativo, contribuindo para alargar possibilidades de muitas crianças, dando-lhes acesso à educação, comporta por vezes riscos para as crianças, que se encontram desprotegidas.

A própria natureza do trabalho doméstico significa que quem o exerce fica fora do alcance dos olhos do mundo, sem protecção contra abusos como o trabalho infantil e o trabalho forçado. Muitas destas crianças ficam ainda mais susceptíveis, quando do sexo feminino, à exploração sexual ou à obrigação de casamento, por vezes, com o homem que as acolhe, com a conivência da primeira mulher, de forma a partilhar as tarefas domésticas.

\section{Casamento forçado}

O casamento forçado pode ocorrer na idade adulta ou na infância/adolescência. Afecta sobretudo o sexo feminino, mas em alguns casos e em determinados contextos os meninos são também obrigados a fazê-lo. Os primeiros casos ocorrem sobretudo em situação de viuvez, já antes apontada no que diz respeito às heranças, e podem ou não incluir a obrigatoriedade de relações sexuais com o detentor da herança (ou seja, podem significar apenas uma passagem simbólica da protecção do marido para a protecção do cunhado, por exemplo, sem necessidade de coabitação). No que diz respeito ao casamento forçado de meninas e raparigas, este tem consequências e características específicas que devem ser tidas em consideração. Em primeiro lugar, dificulta ainda mais o entendimento do consentimento necessário a uma união (consagrado em vários textos jurídicos internacionais, alguns assinados pela Guiné-Bissau e integrados no Código Civil guineense); em segundo lugar, esta prática presume uma relação de poder extremamente desequilibrada (homem mais velho e mulher muito mais nova), o que coloca as meninas em situação de vulnerabilidade acentuada, sobretudo tendo em conta a sua "migração" para casa da família do marido e a perda dos referentes familiares. 
As consequências vão desde a maternidade precoce ao abandono escolar, muito mais acentuado nas raparigas do que nos rapazes. Os objectivos das famílias são o controlo da sexualidade e reprodução fora do casamento e os ganhos económicos (por vezes, as famílias das noivas comprometem-se com a família do noivo ou com o próprio ainda na infância e dele vão recebendo apoios até ao casamento). Para os "noivos" os motivos são vários: desde o estatuto social, ao interesse sexual e de aquisição de mão-de-obra, até terem investido já na família da noiva antes da consumação do casamento.

A idade mais ou menos comum do casamento para as meninas, dependendo da etnia e situação económica, situa-se entre os 12 e os 16 anos, sendo que quanto mais jovem for a menina maior a possibilidade de esta não recusar o casamento. São cada vez mais as notícias e os casos de raparigas que fogem ao casamento forçado, umas com maior sucesso que outras.

Quando não são bem sucedidas na fuga, acontece sofrerem às mãos da família e da comunidade situações de extrema violência: açoites, humilhação pública, privação de liberdade, etc. ${ }^{10}$ As possibilidades de sucesso dependem das ajudas informais a que conseguem aceder: família ou amigos dispostos a acolhê-las e enfrentar os pais (por vezes, até, pagar-lhes) ou, cada vez mais, a recepção destas meninas por missões católicas e protestantes.

\section{Mutilação Genital Feminina}

Esta é talvez a forma de violência mais mediatizada nos últimos tempos, devido às suas consequências na saúde física e psíquica e ao facto de várias mulheres terem vindo a denunciá-la como uma prática nefasta. Na Guiné-Bissau, esta prática, associada aos rituais de passagem à idade adulta (fanado), afecta cerca de duas mil meninas por ano (ESNU, 2006), sendo a grande maioria islamizada e uma pequena parte pertencente a etnias não islamizadas, que recorrem de forma pouco frequente à excisão feminina. Na maioria dos casos a excisão é feita em péssimas condições sanitárias e sem recurso a anestesia, resultando frequentemente em problemas de saúde e até na morte, em caso extremo. Quando isto acontece, muitas vezes a culpa é atribuída à família (de alguma forma aquela menina estava impura, ou estava predestinado), não existindo conhecimento de criminalização e punição destes factos.

As consequências das excisões variam segundo o tipo e a gravidade da intervenção praticada. Segundo a OMS (1999), a forma de excisão praticada na Guiné-Bissau corresponde à excisão ou clitoridectomia (Tipo II), que

${ }_{10}$ Veja-se o artigo: "Noivas em fuga: do sul até à capital, procuram refúgio nas missões - dezenas de jovens guineenses escapam como podem à violência do casamento forçado", Expresso, 20 de Janeiro de 2007. 
inclui a ablação do clítoris e pequenos lábios. Não parece ser o caso, como em outras partes do mundo, em que a excisão se refere apenas à remoção do prepúcio, ou seja, da pele que cobre o clítoris, e que, ao deixá-lo mais exposto, facilitaria a obtenção de prazer (INDE, 2005).

As consequências de não passar pelo fanado podem ser a discriminação e exclusão social, passando pela recusa do casamento ou, quando este sucede, existir exclusão dentro da família no que diz respeito a determinadas tarefas. As mulheres não excisadas são vistas como impuras e sexualmente insaciáveis, levando muitas mulheres adultas a recorrer à excisão, ainda que lhe tenham escapado quando crianças. A idade de excisão localizar-se-á pelos 10 anos; no entanto tem vindo a ser praticada cada vez mais cedo, de forma a que não se descubra tão facilmente.

As razões desta prática e a sua permanência em contexto de mudanças sociais e culturais são várias, implicam diferentes agentes e formas de legitimação. De acordo com Elsa Santiago (2007), entre as principais razões apontadas pelas famílias contam-se as seguintes: atenuar o desejo sexual na mulher e aumentar o prazer sexual do homem; reservar a castidade e a virgindade antes do casamento e a fidelidade durante o casamento, duma forma geral evitar a promiscuidade; aumentar a fecundação e a sobrevivência dos descendentes; promover a identificação com a herança cultural e a integração social; iniciar as raparigas na condição de mulheres e levar à sua purificação; aumentar as oportunidades de casamento e honrar a família.

Por seu turno, o relatório da INDE (2005) assinala outras razões apontadas pelos líderes religiosos: a excisão é uma demonstração de respeito para com as mulheres, bem como uma tradição religiosa que não deve deixar de ser feita; as mulheres não excisadas tornam-se promíscuas e até bissexuais, sendo a excisão uma forma de controlo do seu comportamento (decoro).

A responsabilidade das mulheres na perpetuação desta prática, enquanto mães e enquanto fanatecas, ${ }^{11}$ é já lugar-comum na desculpabilização da prática. No entanto, segundo as entrevistas realizadas, parece claro que esta se perpetua para benefício e por desejo dos homens, que continuam a preferir mulheres excisadas e a ceder às pressões para que a mutilação ocorra.

Muitas vezes, também, procura-se justificar a permanência do fanado por razões económicas, remetendo-se para a festa envolvida, que dura semanas, com benefícios para alguns agentes económicos, para além das fanatecas. No que diz respeito aos rituais e à festa, este pode ser um aspecto a considerar; no entanto, não se justifica que a prática concreta do corte dos órgãos genitais permaneça e não se transforme.

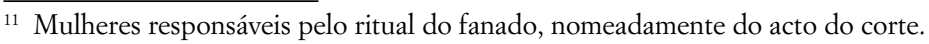


Assim, a grande responsabilidade pode ser repartida entre líderes religiosos e líderes políticos. Os primeiros porque continuam a manipular os textos religiosos, fazendo com que a maior parte da população, incluindo as mulheres, continuem a acreditar que esta prática é obrigatória no Islão. A prática é anterior ao aparecimento da religião muçulmana, não faz parte dos requisitos obrigatórios (é facultativa) nem das leis mais vinculativas do Islão e a mutilação não se pratica na maior parte do mundo islamizado, nomeadamente nos países árabes. Os segundos, porque se demitem de uma actuação vigorosa neste campo, não só em termos de legislação específica (embora a lei geral que diz respeito a danos corporais e psicológicos possa ser aplicada, uma lei específica poderia ter um efeito educativo importante), como no que respeita à permissividade em relação à instalação de barracas de fanado na cidade de Bissau.

Esta demissão política torna infrutíferas as tentativas promissoras de dissuasão destas práticas junto dos líderes tradicionais com capacidade para alterar a situação.

\section{Agressões e abusos por agentes públicos (institucionais)}

$\mathrm{Na}$ Guiné-Bissau, as mulheres estão, muitas vezes, mais expostas a determinados tipos de violência levados a cabo por agentes do Estado no suposto exercício das suas funções. Um desses casos diz respeito às bideiras, ${ }^{12}$ que estão sujeitas a actos de extorsão por parte da polícia e dos militares e a agressões físicas quando tentam escapar a este tipo de actividade. ${ }^{13}$

Outro exemplo grave diz respeito ao tratamento dado às mulheres grávidas e parturientes por parte de pessoal do hospital ou centro de saúde. ${ }^{14}$

Além da extorsão material, negligência e não prestação de cuidados, as parturientes estão, muitas vezes, expostas a maus tratos, dentro e fora dos centros de saúde, uma vez que certas etnias consideram que as dificuldades de parto e/ou a morte da criança são uma manifestação dos "irãs" (deuses)

\footnotetext{
${ }^{12}$ Vendedoras ambulantes.

13 "Quantas vezes as mulheres que vendem peixe no mercado da estrada do Caracol são vítimas de actos selvagens por parte dos militares que por ali passam para cobrar os impostos de utilização dos espaços? Não só as agridem como levam toda a sua mercadoria porque aparentemente não têm as contas regularizadas. Na realidade muitas delas são obrigadas a pagar duas vezes: aos militares e às Finanças" (entrevista a jovem mulher em Bissau, 2006).

${ }_{14}$ Assiste-se hoje no hospital nacional Simão Mendes, o maior centro hospitalar de referência no país, a um "tsunami" sanitário em que as grávidas são obrigadas a pagar a quantia exorbitante de 50.000 Francos CFA na maternidade para serem submetidas a uma intervenção cirúrgica (cesariana), mesmo nos casos de manifesta ausência de meios por parte dos pacientes. Aliás, já houve relatos nos órgãos de comunicação social que dão conta que ainda este ano uma senhora, cujo parto não correu bem, foi obrigada a pagar os ditos 50.000 Francos CFA, caso contrário não sairia nem levaria o cadáver do nado morto para enterrar (Liga Guineense dos Direitos Humanos, 2006).
} 
pela infidelidade da mãe ao marido. Assim, a mulher é submetida a maus tratos por vezes ainda durante o trabalho do parto como castigo pelo seu crime (Santiago, 2007).

\section{Moçambique}

Entre Janeiro e Outubro de 2006, o Gabinete de Atendimento à Mulher e Criança Vítimas de Violência registou, em todo o país, 5302 casos de violência contra mulheres. ${ }^{15}$ No mesmo período de 2007 foram assistidas pela mesma instituição mais de 5600 mulheres. ${ }^{16}$ Sendo que a violência reportada está longe da que é cometida, estes dados encontram-se aquém do quadro global da violência vivida. Os resultados do Inquérito internacional sobre a violência contra a mulher em Moçambique (CEP, 2005) traçam um retrato preocupante. $^{17}$

A violência contra a mulher é, de acordo com Conceição Osório e Eulália Temba (2003: 172), uma componente estruturante das relações entre homens e mulheres em Moçambique, que conferem à mulher uma posição de subordinação. As autoras afirmam que as próprias mulheres reconhecem ao homem esse direito, tornando a violência mais eficaz.

\section{Formas de violência}

Das 1927 mulheres entrevistadas no âmbito do inquérito acima mencionado, $54,2 \%$ já experimentaram violência perpetrada por um homem em algum momento da sua vida; $49,9 \%$ das inquiridas sofreram violência física e 22,8\% foram vítimas de violência sexual (CEP, 2005: 27).

No que diz respeito à violência física, a forma mais comum é esbofetear, pontapear, morder ou esmurrar $(69,9 \%) .17,9 \%$ das mulheres violentadas fisicamente afirmam que um homem the atirou algum objecto e $11,9 \%$ que um homem usou ou ameaçou usar uma faca ou arma contra elas. No que diz respeito à violência sexual, a forma mais frequente é um homem apalpar sexualmente uma mulher $(44,6 \%$ do número de mulheres que sofreram

\footnotetext{
${ }_{15}$ Dados fornecidos por Lurdes Mabunda, responsável do Gabinete de Atendimento à Mulher e Criança Vítimas de Violência, em Dezembro de 2006, durante a apresentação pública do Inquérito Internacional sobre Violência Contra a Mulher 2004.

${ }^{16}$ Cf. http://www.unicef.org/mozambique/pt/media_4320.html.

17 Este estudo fez parte do projecto International Violence Against Women Survey - IVAWS, cujos objectivos passam por compreender a violência contra a mulher em diferentes países. Segundo o estudo de Moçambique, implementado pelo Centro de Estudos da População, em coordenação com a United Nations Office on Drugs and Crime, o Ministério da Mulher e da Acção Social, o PNUD e outras organizações moçambicanas e estrangeiras, mais de metade das inquiridas afirmou ter sofrido uma qualquer forma de violência perpetrada por um homem em algum momento da sua vida; que grande parte dos actos de violência são perpetrados por parceiros íntimos; e que a apresentação de queixa às autoridades sobre incidentes de violência é muito baixa.
} 
violência sexual) e um homem forçar a mulher a ter relações sexuais $(40,3 \%)$ ou tentar forçar $(38,9 \%)$ (ibid.: 41 .)

O inquérito perguntava às mulheres sobre formas de violência em geral, não pretendendo limitar-se à esfera doméstica. Contudo os resultados permitiram concluir que os parceiros íntimos (marido ou namorado actual ou antigo) são os principais perpetradores: $31,8 \%$ das mulheres que tinham parceiro no momento do inquérito foram alvo de violência física ou sexual pelo mesmo e $43,9 \%$ das mulheres que tiveram em qualquer momento da vida um parceiro foram também alvo de violência (ibid:: 43).

No que diz respeito à violência na esfera doméstica, em particular por parte de um parceiro, as mulheres estão sujeitas a formas de violência que vão além das categorias definidas naquele inquérito. É que nos mostra, por exemplo, Terezinha da Silva, segundo a qual, para além das agressões físicas, a violência pode assumir muitas outras formas:

[...] a perseguição no local de trabalho, a recusa em contribuir para as despesas da casa, a destruição das mobílias e de outros bens domésticos, chantagens diversas, a difamação na família e na vizinhança com a atribuição de amantes e outros insultos, a humilhação ao trazer amantes para casa e as ameaças com ou sem armas, situações muitas vezes associadas à violência física (2003: 149-150).

Associada à questão da violência, em geral, e da violência económica, em particular, está a questão da propriedade. Em regra, a casa pertence ao chefe de família. Se a mulher sai de casa, perde o direito aos bens e aos filhos. ${ }^{18}$ Esta situação é instrumentalizada pelos homens para se separarem sem terem que assumir qualquer responsabilidade ou apresentar qualquer motivo. A violência pode ser exercida como meio de levar a mulher a sair de casa (Silva, 2003: 150).

Mejia et al. (2004: 35) chamam a atenção para o facto de o conceito de propriedade não se limitar aos bens materiais do lar, dizendo também respeito à força de trabalho da mulher, pois com frequência é o marido que deve autorizar a mulher a trabalhar. De acordo com Terezinha da Silva (2003: 150) esta situação vem muitas vezes acompanhada da linguagem do amor, ou seja, o controlo do homem sobre a mulher é justificado pelo 'ciúme', pressupondo uma preocupação amorosa. Este tipo de justificação, que tenderá a tornar o controlo mais efectivo, denuncia o carácter de normalidade com que é encarada esta prerrogativa masculina de controlo.

${ }^{18}$ Lurdes Mabunda, responsável do Gabinete de Atendimento à Mulher e Criança Vítimas de Violência, reconhece a necessidade de ter presente esse problema quando se trata um caso de violência. 
Além da violência económica, já mencionada, acrescenta-se à lista a acusação de feitiçaria. ${ }^{19}$ As acusações de feitiçaria são também reveladoras de relações de poder. Segundo Terezinha da Silva (2003: 156), "Tais acusações são feitas por quem detém o poder, transformando-se a vítima dessa acusação num personagem escuso, com poderes maléficos, que deve ser combatido sem recurso de apelação." Acusadas de feitiçaria, as vítimas passam a culpadas, sendo vistas como as instigadoras da violência. Também as viúvas são frequentemente alvo de condenação por parte das famílias do marido. Acusadas de matar por feitiçaria, são expulsas da sua casa e da sua terra.

Como os restantes casos de violências, os homicídios de mulheres por homens na esfera doméstica são o prolongamento e o culminar de um contexto de dominação masculina (WLSA, 2001). Esta é uma das conclusões de um estudo da WLSA ${ }^{20}$ desenvolvido na cidade de Maputo e nas províncias de Gaza, Sofala e Cabo Delgado. Essa situação de dominação está claramente reflectida no modo como os homens procuram legitimar a violência exercida no âmbito conjugal. A desobediência à norma é usada como justificação para o crime.

No que diz respeito às formas de homicídio, as autoras afirmam que os homens usam essencialmente catanas, paus de pilar, facas, mãos e pés e, no caso de Cabo Delgado, armas de fogo e madeira a arder. A província de Cabo Delgado é específica, uma vez que o acentuado consumo de droga e álcool, bem como a posse de armas de fogo, agravam o problema. No entender das autoras, a presença de muitos militares, casados com mulheres originárias de outras províncias, condição que as coloca em situação de particular vulnerabilidade, faz desta província uma área que merece uma abordagem diferenciada (WLSA, 2001).

\footnotetext{
19 "As principais formas de violência doméstica são a agressão física e verbal. Esta segunda é também muito grave. Passa por denegrir a mulher até ao extremo. Pode ser insultos, acusação de feitiçaria, de não dormir em casa. Se o homem não consegue realizar-se sexualmente, a culpa é da mulher, que fez feitiço. Depois, há ainda as questões económicas. O homem vai ao serviço todos os dias, mas não traz dinheiro para casa e não deixa a mulher trabalhar, nem vender, nada! É uma forma de expulsar a mulher de casa sem bater. Depois, quando ela vai embora, ele diz «Onde tu vais? Mas, eu não mandei embora, não bati, já disse que não tenho dinheiro, mas esta mulher gosta muito de dinheiro». Estas acções psicológicas são mais frequentes do que a agressão física. Esta dói mais, age na mente das pessoas. Se for bater, ela às vezes consegue fugir, pode chamar o vizinho. Agora, se ele não dá comida, como é que ela prova?" (Directora executiva da organização Mulher Lei e Desenvolvimento - MULEIDE, entrevista em 27 de Novembro de 2006).

${ }^{20}$ A WLSA (Women and Law in Southern Africa), define-se como uma organização regional cuja missão é contribuir para a melhoria do estatuto legal da mulher na África Austral, através de actividades de investigação-acção da legislação, políticas e práticas sócio-legais, desenvolvendo estratégias de redução das assimetrias de género.
} 
Outra forma de violência contra as mulheres é a mutilação genital feminina. Segundo Lurdes Mabunda ${ }^{21}$ "a mutilação genital feminina é muito pouco falada em Moçambique dada a sua raridade, mas estão surgindo casos e de uma forma grave”. De acordo com a mesma, há famílias do norte de Moçambique que têm vindo a aprender práticas de famílias refugiadas de outros países da África Oriental.

\section{Denunciar a violência}

De acordo com o Inquérito sobre Violência Contra a Mulher (CEP: 2005), a apresentação de queixa às autoridades sobre incidentes de violência é muito baixa: menos de uma em dez vítimas reporta a sua experiência de violência à polícia. Os autores encontram várias explicações para esta constatação: a violência tende a ser vista pelas mulheres como uma questão privada/familiar, preferindo lidar com a situação sozinhas ou na esfera da família alargada; as vítimas não consideram grave o caso de violência; temem represálias do agressor ou que este seja preso. É, no entanto, de salientar que a naturalização da violência doméstica não significa a naturalização da violência do homem sobre a mulher. Daí que Conceição Osório e Eulália Temba (2003: 172) tenham dado conta do aumento do número de queixas contra homens que não pertencem ao agregado familiar.

$\mathrm{Na}$ concepção do senso comum, explica Terezinha da Silva (2003: 145-159), a violência doméstica é um assunto privado, competindo à família a resolução deste tipo de problemas. No entanto, ainda de acordo com a mesma autora, as autoridades oficiais do bairro podem (ou não) ter um papel importante como instâncias mediadoras de conflitos conjugais.

Em Moçambique são inúmeras as instâncias que, com o Estado, partilham o papel de resolução de conflitos. Se estas formas de justiça, pelos baixos custos, a proximidade com as populações e a celeridade podem mostrar-se mais adequadas à promoção do acesso à justiça das mulheres, alguns estudos vêem nelas a reprodução dos modelos patriarcais e da posição subalterna feminina (Araújo, 2005; Arthur e Mejia, 2006; WLSA, 2001; Silva: 2003). Para Arthur e Mejia, a análise dos dados mostra que as agressões são vistas como um não-crime e justificadas pelo desvio da esposa. Segundo as autoras, "apesar das afirmações de que os problemas criminais são canalizados para as instâncias policiais, na verdade isso não acontece” (2006, 6-7). Aliás, do estudo que fazem concluem que, apesar de as mulheres serem as principais

${ }^{21}$ Relatório apresentado por Lurdes Mabunda, responsável do Gabinete de Atendimento à Mulher e Criança Vitimas de Violência, em Dezembro, durante a apresentação pública do Inquérito Internacional sobre Violência Contra a Mulher, 2004. 
mobilizadoras das instâncias locais, a violência física e psicológica só raramente é o fundamento da queixa, sendo em regra referida como argumento para dar mais força a outras denúncias consideradas mais legítimas.

Mas se o modelo de dominação patriarcal está presente na esfera comunitária, não deixa de se ver reflectido na domínio da justiça estatal. Devido a um modelo social que as exclui de um acesso igual aos bens, as mulheres são as maiores vítimas das dificuldades materiais no acesso à justiça. Além disso, também a justiça judicial tende a reproduzir a identificação de determinados problemas da mulher, como o da violência física, com conflitos da esfera privada. Mesmo quando um pedido de divórcio tem como causa directa um espancamento brutal, é desencorajada a apresentação de queixacrime (Osório e Temba, 2003: 176-177). O já referido estudo da WLSA (2001: 95) sobre o homicídio e o femicídio afirma que através dos despachos de pronúncia e dos acórdãos de decisão se constatou "a intervenção de uma perspectiva patriarcal na representação que os agentes de justiça têm do 'significado' e do 'valor' dos actos cometidos por homens e mulheres". Em regra, as mulheres são condenadas a penas mais altas e, "de forma geral, os agentes da justiça declaram a não intencionalidade do crime por parte do homem, considerando implicitamente como justificação a desobediência da mulher".

\section{Angola}

Em Angola, a instabilidade das famílias resultante do conflito e a frustração associadas a um processo deficitário de reintegração de ex-combatentes contribuiu para um aumento dos casos de violência doméstica. São frequentes os relatos de que, regressados às suas comunidades, sem um emprego ou papel activo a desempenhar, e perante a liderança económica assumida por mulheres no interior da família, os antigos combatentes recorrem ao consumo de álcool e à violência intra-familiar como forma de canalização das suas frustrações.

O relatório do Comando de Polícia de Luanda relativo ao ano de $2006^{22}$ registou 399 casos de violência contra a mulher, divididos igualmente em violações sexuais e ofensas corporais. Este número traduz, apenas, os casos chegados ao conhecimento da Polícia. Além disso, segundo dados da Organização de Mulheres Angolanas (OMA), em média existem cerca de vinte registos diários de abuso ou violência contra mulheres (AJPD, 2006: 10).

Outra das expressões crescentes de violência resulta da acção de filhos contra mães, que são espancadas ou mesmo mortas, com o objectivo de se

${ }^{22}$ Gabinete de Estudos Informação e Análise do CPL, Janeiro de 2007. 
apossarem dos seus bens e das suas casas. É, no entanto, fundamental referir também a forma como culturalmente a mulher é vista na sociedade angolana e o poder normalmente exercido sobre esta pelo homem, o que explica que em muitos casos as queixas e denúncias de violência doméstica (em muito maior número aos grupos de apoio das Igrejas do que à polícia nacional e ao sistema judicial) sejam mais resultado de uma incapacidade física e psicológica de continuar a aguentar um determinado tipo de tratamento, do que da noção de que estão a ser sujeitas a abusos e que os seus direitos estão a ser violados. ${ }^{23}$

A ascensão profissional de algumas mulheres, ao contrário do que acontece muitas vezes com os seus maridos, tem constituído um problema, já que o crescimento do rendimento feminino, tanto no sector formal como no sector informal da economia, coloca um desafio cultural à capacidade de gerar rendimentos por parte dos homens.

Finalmente, a dimensão do assédio sexual na sociedade angolana pós-conflito merece alguma atenção. Embora a situação das mulheres e crianças em campos de deslocados internos careça ainda de uma pesquisa aprofundada, testemunhos de funcionários de ONGs com trabalho nesta área indicam que estes grupos continuam a ser vítima de assédio sexual. Por outro lado, e embora não haja dados quantitativos, são várias as descrições, denúncias e relatos sobre casos de abuso sexual de meninas por parte de elementos da polícia nacional em várias províncias, bem como de violação de mulheres que residem perto dos quartéis militares, por exemplo em Luena (província do Moxico) e em Cabinda.

\section{Respostas às violências e algumas conclusões}

As políticas de resposta à violência contra as mulheres tendem a estar segmentadas em diferentes campos de actuação, que nem sempre dialogam entre si, conforme o nível e as expressões das violências em consideração.

Por exemplo, as políticas de ajuda pós-conflito implementadas ao nível macrossocial, pelo Estado, são quase sempre alheias à perspectiva da diferença sexual. Estas políticas assumem-se como políticas de impacto geral e assexuado, quando na realidade está implícita a ideia de que a guerra e a paz são assuntos de homens e se resolvem com as receitas técnicas certas ao nível da economia formal, da boa governação dos assuntos militares.

\footnotetext{
23 "Em Angola, há uma aceitação cultural de bater na mulher. Para mim, a violência doméstica é maior agora que durante a guerra porque há mais poligamia; porque o marido não gosta do que uma mulher faz, the bate e vai ter com uma das outras que tem. E a mulher cala, porque sozinha não consegue sustentar os filhos todos e porque não tem para onde fugir"(Entrevista com Nela, 37 anos, Luanda)
} 
Tal como em outros contextos, na Guiné-Bissau, em Angola e em Moçambique as mulheres retornam aos seus lugares "tradicionais" no final da guerra. Apesar de existir alguma análise sobre as causas da guerra, pouca análise foi feita dos seus impactos.

Os tipos de violências dirigidos especificamente a mulheres ou àqueles que permanecem independentemente do período (conflito, pós-conflito) não são abordados, nem tão pouco os princípios que os legitimam - tipos de construção da masculinidade, utilização da força, impunidade.

Ao mesmo tempo, as questões da violência não entram, em geral, nos debates das estratégias de desenvolvimento. Até agora têm sido vistas como laterais, julgando-se que respostas gerais, de melhoria das condições de vida, levarão naturalmente a uma diminuição da violência. A obsessão com a não interferência directa nos "costumes locais" leva a que uma análise da violência e o desenho de respostas por parte daqueles que estão mais próximos das populações não seja feita. Para a maior parte das ONGs e associações de mulheres, as violências não são uma área relevante de actuação directa, mas sim programas de micro-crédito, de desenvolvimento rural, que podem ter como consequência imprevista não só uma sobrecarga das mulheres (já responsáveis pelo sustento diário da família), mas também alguma desconfiança e reacções violentas por parte dos homens.

As políticas de desenvolvimento de orientação macrossocial continuam a excluir determinadas percepções da feminilidade (tradicional, local, informal, privada) e a promover outras (moderna, modelo externo, formal, pública); ignoram as transformações reais e suas potencialidades e recusam-se a analisar o outro lado das relações de poder e das construções identitárias: os homens e a masculinidade. A aplicação mecânica e irreflectida de fórmulas, sobretudo no discurso dos agentes de desenvolvimento, enquanto forma de captação de fundos, leva ao cansaço face às abordagens "de género" e aumenta a dificuldade em trabalhar questões que estão na base de culturas de violência.

Apesar da perpetuação da violência em tempos de paz se expressar sobretudo no âmbito da família e da comunidade, esta deve ser encarada como um problema nacional e até internacional. Tal não tem sido, contudo, a norma.

Uma das mais recentes respostas internacionais à violência de género em contextos de guerra e de pós-guerra, a Resolução do Conselho de Segurança das Nações Unidas 1325 sobre "Mulheres, Paz e Segurança" (2000), tida como referência no avanço da igualdade de género nas relações internacionais, resume algumas das lacunas apontadas atrás, negligenciando o entendimento da violência de género enquanto expressão e exemplo de mecanismos de reprodução de poder e dominação que permeiam as sociedades em guerra e em paz. 
$\mathrm{Na}$ verdade, apesar da aprovação da Resolução 1325 e das políticas nela inspiradas, nomeadamente as materializadas nos planos de acção nacionais, representar um importante avanço, abrindo caminho às exigências de participação de mulheres em processos de paz e de reconstrução pós-conflito e oferecendo garantias de que as violações de direitos humanos das mulheres sejam tidas em consideração a nível nacional e internacional, permanecem fragilidades e lacunas significativas, na sua maioria reféns dos conceitos de género, violência e (in)segurança que informam a Resolução.

Até à data, a Resolução 1325 tem sido interpretada como dizendo respeito a contextos de guerra e pós-guerra apenas, considerados os locais de ameaça real para mulheres e meninas (sujeitos principais do documento). As ameaças e inseguranças vividas por mulheres e meninas (e também por alguns homens) são, contudo, comuns a vários contextos. Apesar de estas ameaças ou inseguranças terem as mesmas origens, muitas vezes são esquecidas e silenciadas em períodos e contextos que vivem formalmente em paz. Consequentemente marginalizam-se, por um lado, contextos onde se vivem situações de "nem guerra, nem paz" (Dowdney, 2005) e, por outro lado, a prevenção de factores que podem levar ao conflito, em particular o papel preponderante dos indicadores de violências contra as mulheres.

Se estas violências dos 'tempos de paz' fossem tidas em conta, seria de esperar que Estados considerados pacíficos interpretassem a Resolução 1325, procurando indagar o significado e tradução da Resolução nos seus próprios contextos, tendo em conta os continuuns de violência e as manifestações violentas. Além de considerar a Resolução 1325 no campo da política externa, designadamente a política de cooperação para o desenvolvimento, tal envolveria repensar a sua operacionalização, adaptando-a aos contextos de paz formal.

Em suma, apesar de potencialmente revolucionária, uma vez que poderia contribuir para a transformação da forma como a segurança é percebida, protegida e aplicada, a Resolução 1325 contribuiu para a "reciclagem e não para a ressignificação dos termos do debate sobre género, violência e segurança” (Cohn et al., 2004: 137).

\section{Referências bibliográficas}

African Development Bank (2006), Selected Statistics on African Countries, XXV. Tunis:

Statistics Division, Development Research Department.

AJPD (2006), Relatório anual dos direitos bumanos 2005 em Angola. Luanda: AJPD. Araújo, Sara (2005), "Pluralismo jurídico e emancipação social: instâncias comunitárias de resolução de conflitos em Moçambique", communication presented at the 11th 
CODESRIA General Assembly, Rethinking African Development: Beyond impasse, towards alternatives. Maputo. Disponível em http://www.codesria.org/Links/conferences/general_assembly11/papers/araujo.pdf.

Arthur, Maria José (2009), "Imprensa ataca aprovação da Lei da Violência Doméstica”, WLSA (, 7 de Julho). Disponível em http://www.wlsa.org.mz/?blogviewid=29\&_ target (acedido a 7 de Agosto de 2009).

Arthur, Maria José; Mejia, Margarida (2006), "Instâncias locais de resolução de conflitos e o reforço dos papéis de género. A resolução dos casos de violência doméstica", Outras Vozes, 17 (Novembro). Maputo: WLSA Moçambique, 1-7.

Banco Africano do Desenvolvimento (2006), Indicateurs sur le genre, la pauvreté et l'environnement sur les pays africains, VII. Division de statistiques, Département de la Recherche sur le Développement.

Casimiro, Isabel Maria (2004), "Paz na terra, guerra em casa". Feminismo e organizações de mulheres em Moçambique. Maputo: Promédia.

Centro de Estudos da População da Universidade Eduardo Mondlane (CEP) (2005), Inquérito internacional sobre a violência contra a mulher (relatório completo do inquérito). Maputo: CEP.

Cohn, Carol et al. (2004), "Women, Peace and Security: Resolution 1325”, International Feminist Journal of Politics, 6 (1), 30-140.

Dowdney, Luke (2005), Nem guerra, nem paz: comparações internacionais de crianças e jovens envolvidos em violência armada organizada. Rio de Janeiro: 7 Letras.

Ducados, Henda (2000), “An All Men's Show? Angolan Women's Survival in the 30 Year War”, Agenda Magazine, 20, "Women and the Aftermath”. Durban: África do Sul.

Duffield, Mark (2001), Global Governance and the New Wars. Londres: Zed Books.

ESNU - Equipe du Système des Nations Unies (2006), Bilan Commun de Pays/Common Country Assessment (CCA) - Guinée-Bissau, Draft 2, Bissau, Setembro de 2006.

Fórum Mulher; SARDC WIDSAA (2006), "Para além das desigualdades 2005: a mulher em Moçambique”. Maputo e Harare: Fórum Mulher, Maputo e Harare: SARDC.

Fórum Mulher; WLSA (2003), "Lei de família: falemos de igualdade e de justiça”, Outras Vozes, 3, (Maio). Maputo: WLSA Moçambique, 2-8.

Governo República da Guiné-Bissau; PNUD (2004), Premier rapport sur les objectifs du millénaire en Guiné-Bissau

IFAD (2002), “IFAD’s Gender Strengthening Programme in Eastern and Southern Africa - Angola”, Confidential Report, 1328-AO, Agosto 2002.

INDE (2004), "Relatório sobre violações dos direitos das crianças em Bissau". Bissau, 5 de Outubro de 2004.

INDE (2005), Relatório técnico do encontro de líderes religiosos muçulmanos para debate e reflexão sobre a problemática da excisão feminina, Bissau, 5 de Fevereiro de 2005: INDE. 
INE (2001), Questionário de indicadores básicos de bem-estar. Relatório final. Moçambique. Disponível em http://www.ine.gov.mz/inqueritos_dir/quibb (acedido a 25 de Março de 2007).

INE (2003), Resultados do inquérito demográfico e de saúde. Disponível em http://www. ine.gov.mz/inqueritos_dir/inqueritos_dir/ids (acedido a 20 de Março de 2007).

INE (2006a), Inquérito integrado à força de trabalbo. Relatório final. Maputo: INE.

INE (2006b), O sector informal em Moçambique: resultados do primeiro inquérito nacional. Maputo: INE.

Institute for Security Studies (ISS); CEEA; SAS (2004), “Armas ligeiras e segurança em Angola”.

José, André Cristiano; Santos, Boaventura de Sousa (2003), "As ONGs, o acesso à justiça e a defesa dos direitos humanos: a Liga Moçambicana dos Direitos Humanos”, in Boaventura de Sousa Santos; João Carlos Trindade (orgs.), Conflito e transformação social: uma paisagem das justiças em Moçambique. Afrontamento: Porto.

Jacobson, Ruth (2006), "Mozambique and the construction of gendered agency in war", Women's Studies International Forum, 29, Issue 5, September-October 2006, 499-509.

Kaldor, Mary (2000), "Cosmopolitanism and Organised Violence”, comunicação apresentada na conferência Conceiving Cosmopolitanism Conference. Warwick, April 27-29 de Abril de 2000.

Kaldor, Mary (2001), New and Old Wars. Organized Armed Violence in a Global Era. California: Stanford University Press.

Lepri, J. (1993), “En 1993, l'école bissao-guineenne a vint ans”, in C. Cardoso; J. Augel, (eds.), Guiné-Bissau 20 anos de independência: desenvolvimento e democracia. Balanços e perspectivas. Bissau: INEP.

Loforte, Ana Maria (2009), "Os movimentos sociais e a violência contra a mulher em Moçambique: marcos de um percurso”, Outras Vozes, 27, Junho. Disponível em http://www.wlsa.org.mz/?_target_=Tex_MovimentosViolencia (consultado a 7 de Agosto de 2009).

Mané, F. (2004), “A mulher e a criança no sistema jurídico guineense”, Soronda Revista de Estudos Guineenses, Nova série 8, 29-51.

Mejia, Margarita et al. (2004), Não sofrer caladas! Violência contra Mulheres e Crianças: denúncia e gestão de conflito. Maputo: WLSA Moçambique.

Moura, Tatiana (2007), Rostos invisiveis da violência armada. Um estudo de caso sobre o Rio de Janeiro. Rio de Janeiro: 7 Letras.

Organisation Internationale pour les Migrations (OIM) (2004), Rapport de la mission de suivi, evaluation et orientation du programme de démobilisation, réinsertion et réintégration des ex combattants. Bissau: OIM.

Osório, Conceição; Temba, Eulália (2003), “A justiça no feminino”, in Boaventura de Sousa Santos; João Carlos Trindade (orgs.), Conflito e transformação social: uma paisagem das justiças em Moçambique, II, cap. XVIII. Porto: Afrontamento, 165-188. 
Pereira, Franquelina (2004), "Menino de criação versus trabalho doméstico infantil”, comunicação proferida no seminário "Direitos das crianças: a legislação face à tradição”, Bissau 13-15 de Outubro de 2004.

PNUD (2006a), Human Development Report, 2006. Nova Iorque: PNUD.

PNUD (2006b), Relatório nacional do desenvolvimento bumano de Moçambique, 2005. Maputo: PNUD.

Ramsbotham, Oliver (2000), "Reflections on UN Post-Settlement Peacebuilding", in Tom Woodhouse; Oliver Ramsbotham (orgs.), Peacekeeping and Conflict. Londres: Frank Cass, 169-189.

S/A (2007), "Noivas em fuga: do sul até à capital, procuram refúgio nas missões - dezenas de jovens guineenses escapam como podem à violência do casamento forçado", Expresso, 20 de Janeiro de 2007.

Santiago, Elsa (2007), "Violências micro-localizadas", comunicação proferida no workshop "Ajuda e construção da paz em contextos de fragilidade institucional", organizado pelo NEP e pelo INEP, Bissau, 20 de Março de 2007.

Santos, Boaventura de Sousa; Trindade, João Carlos (orgs.) (2003), Conflito e transformação social: uma paisagem das justiças em Moçambique, I e II. Porto: Afrontamento.

Save the Children (2006), disponível em http://www.savethechildren.org/newsroom/2006/ a-mothers-day-report-card.html.

Silva, Terezinha da (2003), "Violência Doméstica: factos e discursos", in Boaventura de Sousa Santos; João Carlos Trindade (orgs.), Conflito e transformação Social: uma paisagem das justiças em Moçambique, II., cap. XVII. Porto: Afrontamento, 143-164.

UNICEF (2007), Multiple Indicator Cluster Survey (MICS) - (2007), Guinea-Bissau. UNICEF.

UNIFEM (2004), "Gender Profile of the Conflict in Angola", http://www.womenwarpeace.org/angola/docs/angola_pfv.pdf.

WIDTECH (1997), "A participação da mulher na reconstrução de Angola no seu processo político e instituições”, projecto realizado para a USAID. Washington: WIDTECH, Julho 1997.

WLSA (2001), Poder e violência. Homicídio e femicídio em Moçambique. Maputo: WLSA Moçambique.

World Bank (2005), "Guinea-Bissau. Integrated Poverty and Social Assessment. Transition from Post Conflict to Long-Term Development: Policy Considerations for Reducing Poverty”, I, Report No. 34553-GW.

World Health Organisation (1999), Female Genital Mutilation - Programmes to date: what works and what doesn't. 